\title{
Prevalence of canine leishmaniasis in Beichuan County, Sichuan, China and phylogenetic evidence for an undescribed Leishmania sp. in China based on 7SL RNA
}

Ke Sun ${ }^{1+}$, Wang Guan ${ }^{1,2+}$, Jian-Guo Zhang ${ }^{1}$, Ya-Jing Wang ${ }^{1}$, Yu Tian ${ }^{1}$, Lin Liao ${ }^{1}$, Bin-Bin Yang ${ }^{4}$, Da-Li Chen ${ }^{1 *}$ and Jian-Ping Chen ${ }^{1,3^{*}}$

\begin{abstract}
Background: Leishmaniasis is a vector-borne disease, which is still endemic in the west and northwest area of China. Canines are the major reservoirs of Leishmania, the etiological agent of human visceral leishmaniasis. Phlebotomus chinensis is the main transmission vector of zoonotic visceral leishmaniasis (ZVL).

Methods: In this study, rK39 dip-stick, ELISA and PCR methods were used to investigate the prevalence of canine leishmaniasis (CanL) in Beichuan County, Sichuan Province, China.

Results: Among the 86 dogs which were included in the study, 13 dogs were positive using the dip-stick test (15.12\%), while 8 dogs were positive using ELISA (9.30\%) and 19 dogs were positive for PCR (22.03\%). In total, 32 dogs were positive for one or more tests (37.21\%). Interestingly, phylogenetic analysis based on the partial 7SL RNA fragment provided evidence that an undescribed Leishmania species, which is clearly a causative agent of CanL and human visceral leishmaniasis, does exist in China. This result is consistent with our previous study.
\end{abstract}

Conclusions: Our work confirmed that canine leishmaniasis is still prevalent in Beichuan County. Further control is urgently needed, as canine leishmaniasis is of great public health importance. The phylogenetic analysis based on 7SL RNA segment provides evidence for the existence of an undescribed Leishmania sp. in China.

Keywords: Prevalence, Canine leishmaniasis, Phylogeny, rK39 dip-stick, Enzyme-linked immunosorbent assay (ELISA), 7SL RNA

\section{Background}

Leishmaniasis is a vector-borne disease caused by different species of the genus Leishmania, including subgenera Viannia and Leishmania. The diseases are characterized by a spectrum of clinical manifestations: cutaneous leishmaniasis (CL), mucocutaneous leishmaniasis (MCL) and visceral leishmaniasis (VL) [1]. Globally, leishmaniasis affects 88 countries, which is an estimated 500,000 cases of VL and 1-1.5 million cases of CL each year [2].

\footnotetext{
* Correspondence: cd11978119@sina.com; jpchen007@163.com ${ }^{\dagger}$ Equal contributors

'Department of Parasitology, School of Preclinical and Forensic Medicine, Sichuan University, Chengdu, Sichuan 610041, China

${ }^{3}$ Animal Disease Prevention and Food Safety Key Laboratory of Sichuan

Province, Sichuan University, Chengdu, Sichuan 610064, China

Full list of author information is available at the end of the article
}

Epidemiologically, canines are the major reservoirs of Leishmania, the etiological agent of human visceral leishmaniasis [3-7]. Following the accelerating urbanization and population mobility, canine leishmaniasis is epidemic in America, Asia and Europe [8-14].

Leishmaniasis is still endemic in China, especially in the west and northwest regions. The prevalence of human leishmaniasis in west China was alarming according to the reports of Wang et al. [15] and Qu et al. [16]. Moreover, as our previous study $[17,18]$ indicated, Leishmania species that are endemic in China is complicated since several species have been reported, including $L$. donovani, L. infantum, L. gerbilli and L. turanica. Interestingly, an undescribed Leishmania species may exist in China, which was reported by Cao et al. [17], Yang et al. [18] 
and Guan et al. [19] using molecular methods. The Dog is the major reservoir in Sichuan province, which belongs to the zoonotic visceral leishmaniasis (ZVL) area [20]. Several sand fly species have been shown to be related to zoonotic visceral leishmaniasis ZVL in the epidemic area of Sichuan Province, such as Phlebotomus chinensis, Sergentomyia koloshanensis, Sergentomyia barraudi and Sergentomyia squamirostris [21]. The number of stray dogs increased after the earthquake that occurred in Wenchuan County, China, on May 12th, 2008, which increased the risk of leishmaniasis outbreaks. Beichuan County was one of the worst affected counties (in terms of destruction) in the Wenchuan great earthquake and the epidemiology of canine leishmaniasis (CanL) has not been reported. Therefore, it is a matter of urgency to survey the prevalence of canine leishmaniasis in Beichuan County, Sichuan, China [22].

Most infected dogs do not show clinical signs. These asymptomatic dogs harbor the parasite, and thus play an important role in the maintenance of the etiological agent of human visceral leishmaniasis [23,24]. Serological analyses and PCR methods have been successfully used to detect Leishmania infection in symptomatic and asymptomatic dogs $[8-11,25]$. Although sero-positivity is found to be very high in symptomatic dogs, it is inefficient in diagnosis of the asymptomatic ones [26,27]. PCR assay can greatly enhance the sensitivity of the diagnosis of Leishmania infection in asymptomatic dogs [25]. The 7 spliced leader (7SL) RNA is a component of the signal recognition particle in eukaryotes [28]. It has been reported that 7SL RNA is highly conserved and can be used to differentiate Leishmania species [29-31].

Thus, in this study we utilized rK39 dip-stick, ELISA and PCR methods targeting 7SL RNA gene to investigate the prevalence of canine leishmaniasis in Beichuan County, Sichuan Province, China. For accurate identification of the Leishmania species prevalent in this area, we further performed phylogenetic inference on the basis of 7SL RNA segments analysis.

\section{Methods}

\section{Study area}

Beichuan County $\left(31^{\circ} 14^{\prime} \sim 32^{\circ} 14^{\prime} \mathrm{N}, 103^{\circ} 44^{\prime} \sim 104^{\circ} 42^{\prime} \mathrm{E}\right)$ is located in the northwest of Sichuan province (Figure 1). Three villages, Mazao, Badi and Dunshang, were chosen to carry out this study. These villages are located in a mountainous area, 800-1200 m above sea level. Houses were rebuilt after Wenchuan great earthquake along the mountains. The population is composed mainly of peasants. Almost every family raised at least one dog as house guardian. Dogs were not allowed to enter the house, and some of them were tied nearby the house, other dogs became stray dogs due to the Wenchuan great earthquake. This county is a known leishmaniasis endemic area, with 1-2 human VL cases reported every year.

\section{Animals and sampling procedures}

Samples were collected from dogs during field trips in September 2011. The study on dogs was approved by the Ethical Review Committee of the National Institute of Parasitic Disease, Chinese Center for Disease Control and Prevention (CDC) in Shanghai. Dogs were sampled in 81 houses where oral informed consent was granted. A total of 86 dogs, numbered as Canine- 1 to Canine- 86 by the phlebotomized succession, were concluded and their age, gender, clinical signs compatible with CanLwere registered [3]. Among the 86 dogs, 7 dogs were from Macao while 64 dogs were from Badi which was the most severe CanL endemic village and 15 dogs were from Dunshang. $2 \mathrm{ml}$ blood samples were obtained from each dog by venipuncture of the foreleg vein, and then numbered according to the dog number. $1 \mathrm{ml}$ blood was stored in sterile, EDTA-coated tubes to extract parasite DNA for PCR tests. The other $1 \mathrm{ml}$ blood was placed in sterile tubes, which were free of anticoagulant, then centrifuged at $2800 \mathrm{rpm}$ for 20 minutes. Sera were collected to detect the specific antigen of Leishmania. All samples were then stored at $-20^{\circ} \mathrm{C}$.

\section{Serological analysis rK39 dip-stick test}

All 86 samples were tested for anti-rK39IgG antibodies in the field using the Kalazar Detect rK39 dip-stick (InBios, USA) according to the manufacturer's protocol.

\section{ELISA test}

A double antibody sandwich method was performed using the Canine leishmaniasis kit (R\&D, USA) to detect the Leishmania antigen in the serum according to the manufacturer's protocol.

\section{Molecular techniques DNA extraction}

DNA was extracted from dog blood samples using Tiangen Blood DNA Kit (Tiangen, China) according to manufacturer's protocol. Leishmania strain MHOM/CN/ 90/SC10H2 was chosen as the positive control and has previously been shown to induce extracellular amastigote transformation by Cao et al. [32]. The parasite was cultured in NNN medium at $24^{\circ} \mathrm{C}$ for 7 days, then amplified in culture in medium 199 supplemented with 15\% heatinactivated fetal bovine serum at $25^{\circ} \mathrm{C}$. Approximately $1 \times 10^{9}-5 \times 10^{9}$ promastigotes were collected by centrifugation at $4,000 \mathrm{rpm}$ for $10 \mathrm{~min}$ at $4^{\circ} \mathrm{C}$ and washed with PBS. Total genomic DNA was extracted from the promastigotes using a standard sodium dodecyl sulfateproteinase $\mathrm{K}$ procedure described by Sambrook and Russell [33]. 


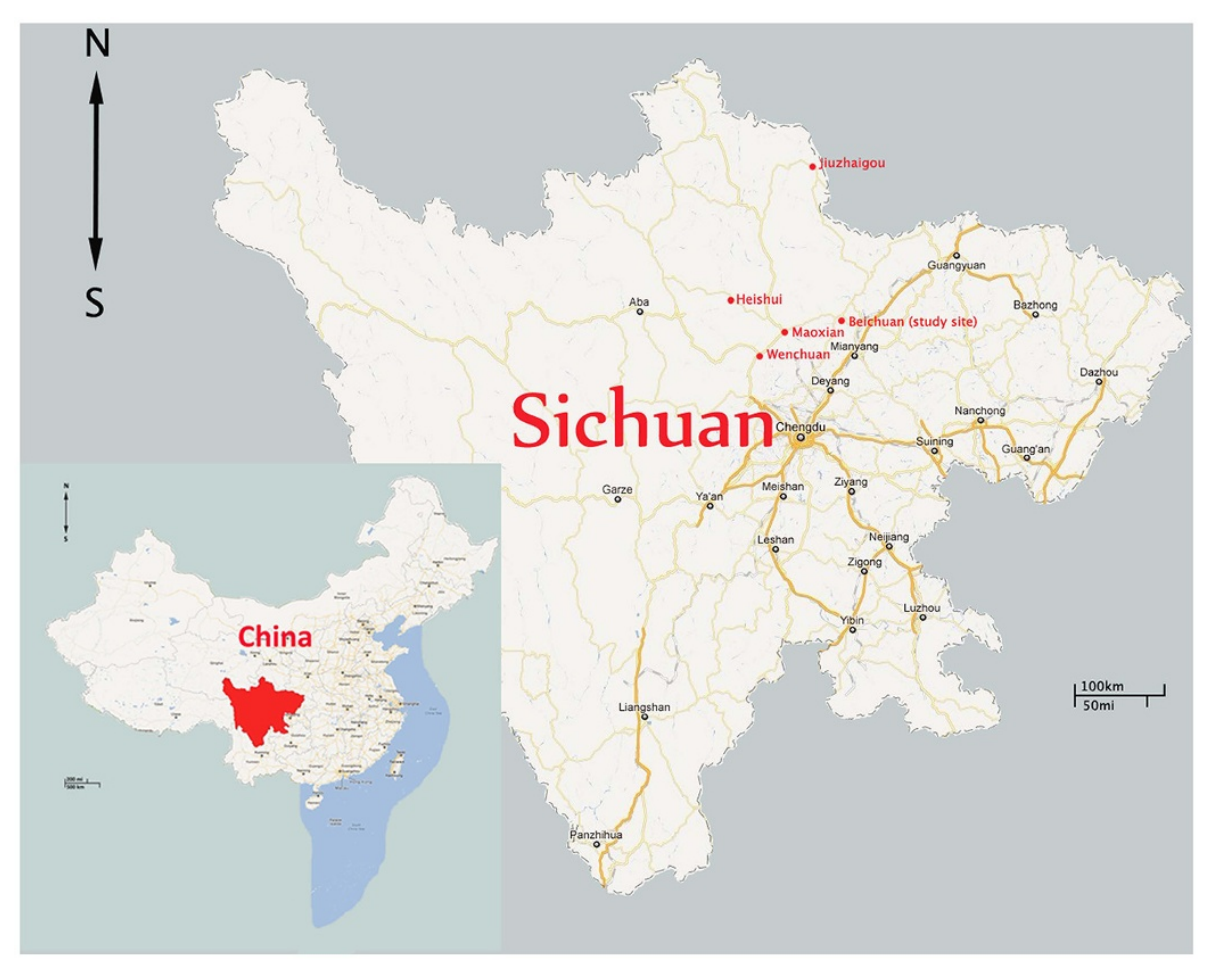

Figure 1 The map of China showing the study area located in the northwest of Sichuan province. The red color marked places are canine leishmaniasis endemic areas.

\section{Detection of genomic DNA by PCR}

The 7SL gene was amplified using the primers described by Zelazny et al. [31]. Primer TRY7SL.For1.M13 (5'GTA AAA CGA CGG CCA GTG CTC TGT AAC CTT CGG GGG CT-3') and TRY7SL. Rev1. M13 (5'-CAG GAA ACA GCT ATG ACG GCT GCT CCG TYN CCG GCC TGA CCC-3') were commercially synthesized and dissolved in nuclease free water to give a working concentration of $10 \mathrm{pMol}$. The PCR tests were performed in Peltier Thermal Cycler (BIO-RAD, USA) with a reaction mixture consisting of $0.5 \mu \mathrm{L}$ Golden Fast DNA Polymerase (Tiangen, China), $12 \mu \mathrm{L} 2 \times$ Golden Fast Reaction Mix, $1 \mu \mathrm{L}$ of forward primer, $1 \mu \mathrm{L}$ of reverse primer, $3 \mu \mathrm{L}$ of extracted DNA, and ultra-pure water to give a final volume of $25 \mu \mathrm{L}$. The PCR thermo cycling program consisted of an initial step at $95^{\circ} \mathrm{C}$ for 5 minutes, followed by 36 cycles at $95^{\circ} \mathrm{C}$ for 15 seconds, $65^{\circ} \mathrm{C}$ for 5 seconds, and $72^{\circ} \mathrm{C}$ for 15 seconds, and a final incubation at $72^{\circ} \mathrm{C}$ for 2 minutes. The PCR products were analysed on a $1.5 \%$ agarose gel stained with ethidium bromide then using a DNA purification kit (Omega, USA) following the manufacturer's protocol. Purified products were sequenced using an ABI BigDye Terminator chemistry on an ABI 3730 automated sequencer with the primer M13 Forward (5'-GTAAAACGACGGC CAG-3') and M13 Reverse (5'-CAGGAAACAGCTAT GAC-3'). The determined sequences were then submitted to GenBank.

\section{Phylogenetic analyses}

A set of 7SL RNA sequences of Leishmania were retrieved from GenBank, including twenty two strains of subgenus Leishmania, eight strains of subgenus Viannia, one strain of Leishmania tarentolae. Trypanosoma brucei was included as an outgroup. The sequences were aligned using Clustal X 1.83 [34] with default gap penalties. The p-distance matrices were computed with MEGA v.4.0.2 [35].

Phylogenetic hypotheses of Leishmania were generated with 7SL RNA segments using Bayesian inference (BI) with the program MrBayes v.3.2 [36]. Gaps were treated as missing data. T. brucei was used to root the trees according to a recent study on the phylogeny of Trypanosomatidae [37]. Prior to phylogenetic analyses, the best-fit model of evolution, GTR + G, was selected using jModelTest v.0.1.1 [38] under the Akaike information criterion [39] following recent recommendations [40]. Posterior probability distribution was estimated by allowing four incrementally heated Markov chains to proceed for four million times, with samples taken from every 200 generations. To ensure our analyses were not restricted from the global optimum, analyses were repeated beginning with different starting trees [41]. The first one million generations were discarded in case this chain reached stationary, and the remaining samples from the independent runs were pooled to obtain the final approximation of 
Table 1 Serology and PCR detection results in dogs living in the three villages, Mazao, Badi and Dunshang

\begin{tabular}{|c|c|c|c|c|c|c|}
\hline Dipstick & ELISA & PCR & No of dogs in Maozao & No of dogs in Badi & No of dogs in Dunshang & Total \\
\hline+ & + & + & 0 & 1 & 0 & 1 \\
\hline+ & + & - & 0 & 0 & 0 & 0 \\
\hline+ & - & - & 1 & 3 & 3 & 7 \\
\hline- & + & + & 0 & 1 & 0 & 1 \\
\hline- & + & - & 0 & 6 & 0 & 6 \\
\hline+ & - & + & 0 & 5 & 0 & 5 \\
\hline- & - & + & 0 & 11 & 1 & 12 \\
\hline- & - & - & 6 & 37 & 11 & 54 \\
\hline Total & & & 7 & 64 & 15 & 86 \\
\hline
\end{tabular}

the posterior distribution of trees. The posterior distribution was summarized as a $50 \%$ majority-rule consensus to form a robust phylogeny. The results of Bayesian analyses were accessed with Treeview v1.6.6 [42].

\section{Results}

\section{Serological and PCR detection results}

A total of 86 dogs were tested. All tested dogs were older than 4-months (going through at least one sand fly season during May to September), males accounted for $64 / 86(74.42 \%)$. None of them presented any clinical signs of CanL. Results of serological tests (including dipstick test and ELISA), PCR are shown in Table 1. 13 dogs were positive for Dipstick test (15.12\%), while 8 dogs were positive for ELISA test (9.30\%) and 19 dogs were positive for PCR (22.03\%). The prevalence in Macao, Badi, Dunshang were 1/7(14.29\%), 27/64(42.19\%), 4/15 (26.67\%) respectively. Globally, 32/86 (37.21\%) dogs were positive for one or more tests.

\section{DNA sequences and phylogenetic analyses}

All the PCR-positive samples were sequenced, and numbered as canine- 10 to canine- 72 according to the dog number. 7SL RNA of the strain MHOM/CN/90/ $\mathrm{SC} 10 \mathrm{H} 2$, which was isolated from human patients in
1990 in Sichuan province was also obtained. GenBank accession numbers of these sequences were JQ315203 to JQ315222. After alignment by Clustal X 1.83, some minor adjustment of the aligned matrix was done by Mega 4.0. Prior to the Bayesian analysis, the most adequate model of evolution GTR $+\mathrm{G}(-\ln L=530.5067)$ was selected by jModeltest.

For the aligned matrix of 7SL RNA, overall mean p-distance was 0.096. The p-distance between each complex was also computed (Table 2). In the phylogenetic tree inferred from this matrix (Figure 2), a clear division was observed between the two subgenera Leishmania and Viannia. Surprisingly, the unisolated Leishmania in our study and strain MHOM/CN/90/SC10H2 formed a clade with nonpathogenic L. tarentolae $(\mathrm{PP}=0.83)$ rather than any other pathogenic Leishmania species, thus termed Leishmania $s p$. The p-distance within this group was 0.00924 . To the other complex, the p-distance ranged from 0.02935 (L. tarentolae) to 0.18022 (L. guyanensis complex).

\section{Discussion}

Leishmaniasis is still endemic in Sichuan, China, with over 100 cases reported every year [32]. The environment was vastly altered due to the Wenchuan great earthquake in 2008. As a result of that, stray dogs were increasing. Similar

Table 2 Pairwise genetic distances for 7SL RNA segments among Leishmania strains in this study

\begin{tabular}{|c|c|c|c|c|c|c|c|c|c|}
\hline & & 1 & 2 & 3 & 4 & 5 & 6 & 7 & 8 \\
\hline 1 & Leishmania sp. & & & & & & & & \\
\hline 2 & T. brucei & 0.30043 & & & & & & & \\
\hline 3 & L. tropica complex & 0.09526 & 0.25758 & & & & & & \\
\hline 4 & L. tarentolae & 0.02935 & 0.27068 & 0.12409 & & & & & \\
\hline 5 & L. mexicana complex & 0.08086 & 0.25824 & 0.05184 & 0.09512 & & & & \\
\hline 6 & L. major complex & 0.10255 & 0.26515 & 0.03650 & 0.13139 & 0.07441 & & & \\
\hline 7 & L. donovani complex & 0.06565 & 0.27850 & 0.05846 & 0.09430 & 0.06591 & 0.06576 & & \\
\hline 8 & L. guyanensis complex & 0.18022 & 0.32090 & 0.18978 & 0.20290 & 0.18046 & 0.18248 & 0.17305 & \\
\hline 9 & L. braziliensis complex & 0.17302 & 0.31343 & 0.18248 & 0.19565 & 0.17438 & 0.17518 & 0.16684 & 0.00719 \\
\hline
\end{tabular}




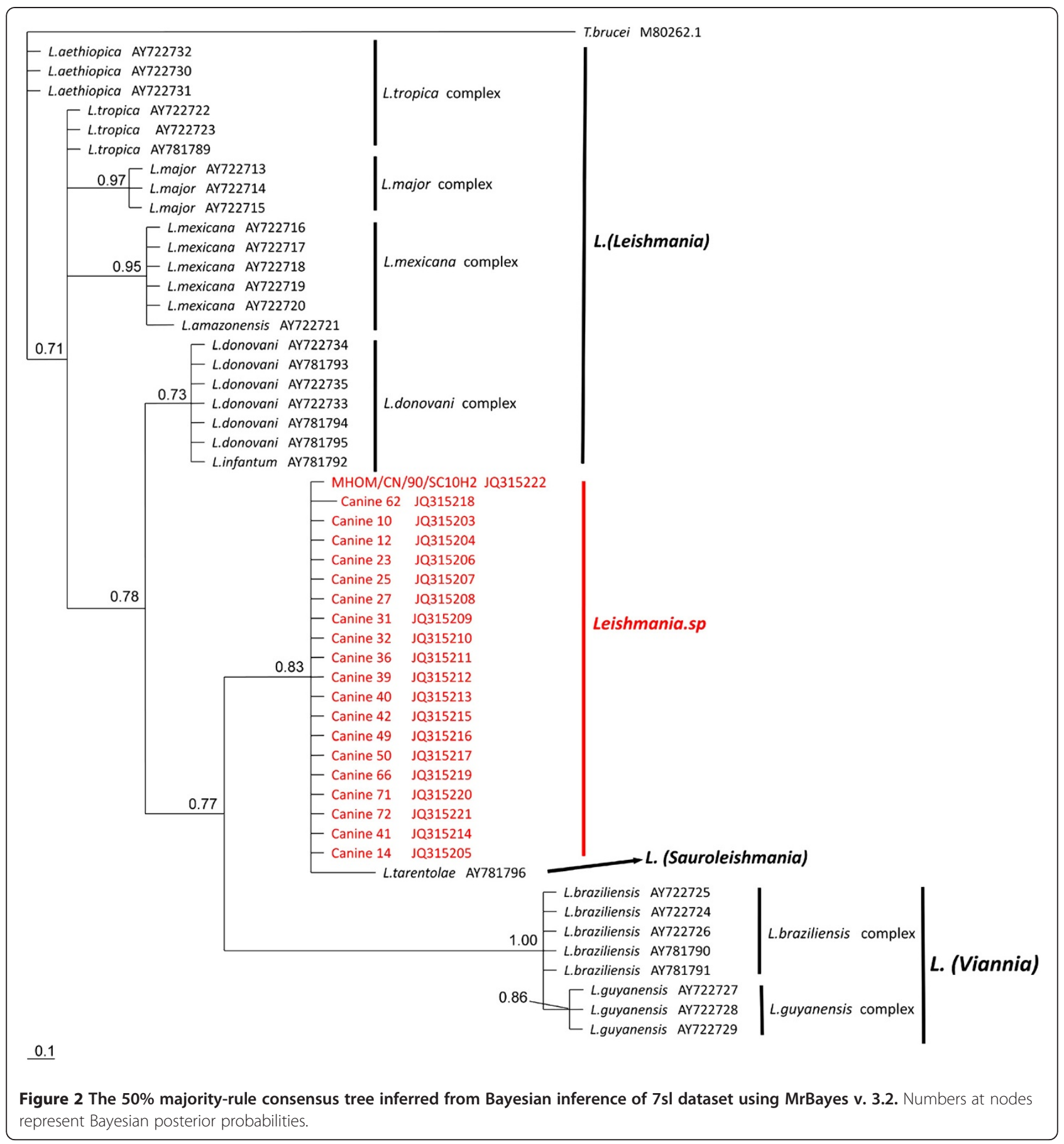

studies focusing on Jiuzhaigou County, Wenchuan County and Heishui County of Sichuan Province indicated that, the rate of positive dogs for CanL tests was high, especially in asymptomatic dogs, which highlights the risk of the potential leishmaniasis outbreaks in these counties [20,43]. As Beichuan County is geographically adjacent to Jiuzhaigou County, Wenchuan County, it is also very important to investigate the prevalence of CanL in this county.
In this study, a total of 86 dogs were tested for CanL using rK39 dip-stick, ELISA and PCR methods. PCR targeting 7SL RNA presented a higher positive rate than rK39 dip-stick and ELISA methods $(22.03 \%$ versus $13.95 \%$ and $9.30 \%$ ). Reasonable explanations are: (1) Firstly, the anti-rK39 IgG antibodies were only detected by rK39 dip-stick when active infection occurs [20]. Thus, the sensitivity of rK39 dip-stick would be restricted when 
applied in non-active infection stages; (2) Secondly, the ELISA method detects Leishmania antigens via specific antigen-antibody reaction. However, if the load of Leishmania in samples is too low to be detected, the usefulness of the ELISA method will be limited; (3) Most importantly, a recombinant antigen of $L$. chagasi was used in rK39 dip-stick, while an anti-L. donovani antibody was used in the ELISA method. As both L. chagasi and L. donovani belong to $L$. donovani complex, it would be unreliable to use these methods to detect leishmaniasis caused by other Leishmania species [44]. In comparison to the studies of Wang and Shang [20,43], our PCR test result showed lower positive rates (22.03\% versus $51.88 \%$ and $24.8 \%$ ). A reasonable deduction is that we chose newly described 7SL RNA as PCR target rather than traditional, sensitive kDNA minicycle. However, 7SL RNA has an advantage over kDNA minicycle, as it can clearly differentiate Leishmania species, while the genus-specific kDNA minicycle is relatively inefficient in species discrimination $[45,46]$. It is quite useful in our study, as our knowledge of Leishmania strain prevalent in China is scarce. However, the sensitivity of conventional PCR methods are usually low, new and advanced methods should be used, such as High-resolution melt analysis PCR (HRM PCR) [47], Real-Time PCR [48], reverse dot blot assay [29] which can vastly enhance sensitivity. In total, $37.21 \%$ of the dogs tested were positive for one or more tests, which highlight the potential risk of leishmaniasis outbreak in this area. Further surveillances and control measures are urgently needed.

The most reliable marker for the species discrimination and phylogenetic analysis within the genus Leishmania is Hsp70 gene [49], and phylogenetic tree based on 7SL RNA [31] shared a similar topology with the tree based on Hsp70, which ensures the phylogenetic analysis based on 7SL RNA is robust. In our analysis, the phylogenic tree based on 7SL RNA also showed a similar topology to the tree based on Hsp70 [49]. Interestingly, the 7SL RNA sequences obtained in this study did not form a clade with any known pathogenic Leishmania species, but formed a clade, which was most closely related to the nonpathogenic L. tarentolae. The strain MHOM/CN/90/SC10H2, which was isolated in a VL patient, was also in this clade. The topology is congruent with our previous studies based on COII, 18 S rRNA and 7SL RNA $[17,19]$. This result provides evidence that an undescribed Leishmania species, which is clearly a causative agent of CanL and human VL, does exist in China. Although the phylogeny based on 7SL RNA indicates these unisolated Leishmania are most closely related to L. tarentolae, however, our knowledge on the geographical distribution of $L$. tarentolae is rare and valid $L$. tarentolae strains are scarce. In the meantime, we are also unclear of the geographical distribution of the Leishmania sp., as known Leishmania sp. strains were rare. Therefore, as the genetic relationship is more related to geography rather than clinical effects [50], it would be hasty to deduce the evolutionary relationship between these two. Thus, more isolates of Leishmania sp. and L. tarentolae from different areas would add to our understanding of this issue. Also, traditional multilocus enzyme electrophoresis (MLEE) methods and newly designed Multilocus Sequence Analysis (MLSA) methods must be combined to validate this undescribed Leishmania sp. in China.

\section{Conclusions}

In conclusion, we investigated the prevalence of canine leishmaniasis in Beichuan County, Sichuan Province, China, based on rK39 dip-stick, ELISA and PCR methods. A total of 86 dogs were tested. Among them, 13 dogs were positive using the Dipstick test (15.12\%), while 8 dogs were positive using the ELISA test (9.3\%) and 19 dogs were positive for PCR (22.03\%). Global prevalence, 32/86 (37.21\%) dogs were positive for one or more tests. Interestingly, phylogeny based on the partial 7SL RNA segments showed these unisolated Leishmania did not belong to any known pathogenic Leishmania species, but formed a distinct group closely related to nonpathogenic L. tarentolae. Our findings provide evidence that: (1) an undescribed Leishmania species, which is clearly a causative agent of CanL and human VL, does exist in China; (2) the prevalence of canine leishmaniasis is very high in Beichuan County, further surveillance and control measures are urgently needed.

\section{Competing interests}

The authors declare that they have no competing interests.

\section{Acknowledgement}

We would like to thank Fei Wang (Beichuan CDC), Fei Liu (Beichuan CDC) and Fu-Nan Zhang (Sichuan Province CDC) for their kind assistance in field sampling. This study is supported by grants from the National Natural Sciences Foundation of China (No. 81171607, No. 30800094 and No. 30771883) and the National Project of Important Infectious Diseases (No. 2008-ZX10004-011).

\section{Author details}

'Department of Parasitology, School of Preclinical and Forensic Medicine, Sichuan University, Chengdu, Sichuan 610041, China. ${ }^{2}$ Department of Parasitology, North Sichuan Medical College, Nanchong, Sichuan 637000, China. ${ }^{3}$ Animal Disease Prevention and Food Safety Key Laboratory of Sichuan Province, Sichuan University, Chengdu, Sichuan 610064, China. ${ }^{4}$ Institute of Laboratory Medicine, Ningxia Medical University, Yinchuan, 750004, China

\section{Authors' contributions}

KS and WG carried out the study, participated in the sequence alignment, phylogenetic analysis and drafted the manuscript. LL carried out the culture of Leishmania strain MHOM/CN/90/SC10H2. JGZ and BBY participated in the ELISA assay. YT and YJW participated in the sequence alignment and phylogenetic analysis. DLC and JPC designed the study and participated in drafting the manuscript. All authors read and approved the final version of this manuscript.

Received: 21 February 2012 Accepted: 19 April 2012

Published: 19 April 2012 
References

1. Reithinger R, Dujardin JC, Louzir H, Pirmez C, Alexander B, Brooker S: Cutaneous leishmaniasis. Lancet Infect Dis 2007, 7:581-596.

2. Desjeux P: Leishmaniasis: current situation and new perspectives. Comp Immunol Microbiol Infect Dis 2004, 27:305-318.

3. Baneth G, Koutinas AF, Solano-Gallego L, Bourdeau P, Ferrer L: Canine leishmaniosis-new concepts and insights on an expanding zoonosis: part one. Trends Parasitol 2008, 24:324-330.

4. Dantas-Torres F: The role of dogs as reservoirs of Leishmania parasites, with emphasis on Leishmania (Leishmania) infantum and Leishmania (Viannia) braziliensis. Vet Parasitol 2007, 149:139-146.

5. Quinnell RJ, Courtenay O: Transmission, reservoir hosts and control of zoonotic visceral leishmaniasis. Parasitol 2009, 136:1915-1934.

6. Palatnik-de-Sousa CB, Day MJ: One Health: the global challenge of epidemic and endemic leishmaniasis. Parasit Vectors 2011, 4:197.

7. Menn B, Lorentz S, Naucke TJ: Imported and travelling dogs as carriers of canine vector-borne pathogens in Germany. Parasit Vectors 2010, 3:34.

8. Aoun O, Mary C, Roqueplo C, Marié JL, Terrier O, Levieuge A, Davoust B: Canine leishmaniasis in south-east of France: screening of Leishmania infantum antibodies (western blotting, ELISA) and parasitaemia levels by PCR quantification. Vet Parasitol 2009, 166:27-31.

9. Dantas-Torres F: Canine leishmaniosis in South America. Parasit Vectors 2009, 2(Suppl 1):S1

10. Duprey ZH, Steurer FJ, Rooney JA, Kirchhoff LV, Jackson JE, Rowton ED, Schantz PM: Canine visceral leishmaniasis, United States and Canada, 2000-2003. Emerg Infect Dis 2006, 12:440-446.

11. Kovalenko DA, Razakov SA, Ponirovsky EN, Warburg A, Nasyrova RM, Ponomareva VI, Fatullaeva AA, Nasereddin A, Klement E, Alam MZ, Schnur $L F$, Jaffe $C L$, Schönian G, Baneth G: Canine leishmaniosis and its relationship to human visceral leishmaniasis in Eastern Uzbekistan. Parasit Vectors 2011, 4:58.

12. Megat-Abd-Rani PA, Irwin PJ, Gatne M, Coleman GT, Traub RJ: Canine vector-borne diseases in India: a review of the literature and identification of existing knowledge gaps. Parasit Vectors 2010, 3:28.

13. Otranto D, Dantas-Torres F: Canine and feline vector-borne diseases in Italy: current situation and perspectives. Parasit Vectors 2010, 3:2.

14. Miro G, Checa R, Montoya A, Hernandez L, Dado D, Galvez R: Current situation of Leishmania infantum infection in shelter dogs in northern Spain. Parasit Vectors 2012, 5:60

15. Wang JY, Feng Y, Gao CH, Jin CF, Chen SB, Zhang CJ, He JP, Yang CM, Yang YT, Bao YF: Asymptomatic Leishmania infection in human population of Wenxian County, Gansu Province. Chin J Parasitol Parasit Dis 2007, 25:62-64 (in Chinese with English abstract).

16. Qu JH, Wang HF, Zhao GH, Zhong WX, Kai SE, Dou HP, Cui Y, Li J, Kong FH: Survey of Leishmania donivani infection in humans in Kashi City of Xinjiang Uggur Autonomous region. China Tropical Medicine 2010, 10:1324-1327. (in Chinese with English abstract).

17. Cao DP, Guo XG, Chen DL, Chen JP: Species delimitation and phylogenetic relationships of Chinese Leishmania isolates reexamined using kinetoplast cytochrome oxidase II gene sequences. Parasitol Res 2011, 109:163-173.

18. Yang BB, Guo XG, Hu XS, Zhang JG, Liao L, Chen DL, Chen JP: Species discrimination and phylogenetic inference of 17 Chinese Leishmania isolates based on internal transcribed spacer 1 (ITS1) sequences. Parasitol Res 2010, 107:1049-1065.

19. Guan W, Cao DP, Sun K, Xu JN, Zhang JR, Chen DL, Chen JP: Phylogenic analysis of Chinese Leishmania isolates based on mall subunit ribosomal RNA (SSU rRNA) and 7 spliced leader RNA (7SL RNA). Acta Parasitologica, 2012, 57(2):101-113.

20. Wang JY, $\mathrm{Ha}$ Y, Gao CH, Wang Y, Yang YT, Chen HT: The prevalence of canine Leishmania infantum infection in western China detected by PCR and serological tests. Parasit Vectors 2011, 4:69.

21. Wei F, Shang L, Jin H, Lian H, Liu W, Li Z, Gao H, Liu Q: Molecular detection and genetic diversity of Leishmania donovani in naturally infected Phlebotomus chinensis from southwestern China. Vector Borne Zoonotic Dis 2011, 11(7):849-852.

22. Wang Q, Li SZ, Qian YJ, Wang JY, Wu WP, Wang RR, Wang LY, Zhou XN: Preliminary evaluation on the transmission potential of visceral leishmaniasis after earthquake in Wenchuan. Zhong guo Ji Sheng Chong Xue Yu Ji Sheng Chong Bing Za Zhi 2008, 26:236-238. (in Chinese with English abstract).
23. Lima LV, Carneiro LA, Campos MB, Chagas EJ, Laurenti MD, Corbett CE, Lainson R, Silveira FT: Canine visceral leishmaniasis due to Leishmania (L.) infantumchagasi in Amazonian Brazil: comparison of the parasite density from the skin, lymph node and visceral tissues between symptomatic and asymptomatic, seropositive dogs. Rev Inst Med Trop Sao Paulo 2010, 52:259-265.

24. Moshfe A, Mohebali M, Edrissian G, Zarei Z, Akhoundi B, Kazemi B, Jamshid S, Mahmoodi M: Canine visceral leishmaniasis: asymptomatic infected dogs as a source of L. infantum infection. Acta Trop 2009, 112:101-105.

25. Miró G, Cardoso L, Pennisi MG, Oliva G, Baneth G: Canine leishmaniosis-new concepts and insights on an expanding zoonosis: part two. Trends Parasitol 2008, 24:371-377

26. Porrozzi R, Santos-da-Costa MV, Teva A, Falqueto A, Ferreira AL, dos Santos CD, Fernandes AP, Gazzinelli RT, Campos-Neto A, Grimaldi G Jr: Comparative evaluation of enzyme-linked immunosorbent assays based on crude and recombinant leishmanial antigens for serodiagnosis of symptomatic and asymptomatic Leishmaniainfantum visceral infections in dogs. Clin Vaccine Immunol 2007, 14:544-548.

27. Solano-Gallego L, Morell P, Arboix M, Alberola J, Ferrer L: Prevalence of Leishmania infantum infection in dogs living in an area of canine leishmaniasis endemicity using PCR on several tissues and serology. J Clin Microbiol 2001, 39:560-563.

28. Walter P, Blobel G: Signal recognition particle contains a 7 S RNA essential for protein translocation across the endo-plasmic reticulum. Nature 1982, 299:691-698.

29. Azmi K, Nasereddin A, Ereqat S, Schönian G, Abdeen Z: Identification of Old World Leishmania species by PCR-RFLP of the 7 spliced leader RNA gene and reverse dot blot assay. Trop Med Int Health 2010, 15:872-880.

30. Nasereddin A, Jaffe CL: Rapid diagnosis of Old World Leishmaniasis by high-resolution melting analysis of the 7SL RNA gene. J Clin Microbiol 2010, 48:2240-2242.

31. Zelazny AM, Fedorko DP, Li L, Neva FA, Fischer SH: Evaluation of 7SL RNA gene sequences for the identification of Leishmaniaspp. AmJTrop Med Hyg 2005, 72:415-420.

32. Cao DP, Chen DL, Chen JP, Liao L, Yang BB, Hu XS: Axenic culture and identification of amastigotes from Sichuan human strain of Chinese Leishmania isolates. Vet Parasitology 2012, 183:353-355.

33. Sambrook J, Russell DW: Molecular cloning: a laboratory manual. 3rd edition. New York: Cold Spring Harbor Laboratory Press; 2001.

34. Thompson JD, Gibson TJ, Plewniak F, Jeanmougin F, Higgins DG: The Clustal X Windows interface: flexible strategies for multiple sequence alignment aided by quality analysis tools. Nucleic Acids Res 1997, 25:4876-4882.

35. Tamura K, Dudley J, Nei M, Kumar S: MEGA4: molecular evolutionary genetics analysis (MEGA) software version 4.0. Mol Bio Evol 2007, 24:1596-1599.

36. Ronquist F, Huelsenbeck JP: MrBayes 3: Bayesian phylogenetic inference under mixed models. Bioinformatics 2003, 19:1572-1574.

37. Hughes L, Piontkivska H: Phylogeny of Trypanosomatidae and Bodonidae (Kinetoplastida) based on $18 \mathrm{~S}$ rRNA: evidence for paraphyly of Trpanosoma and six other genera. Mol Biol Evol 2003, 20:644-652.

38. Poasda D: jModelTest: phylogenetic model averaging. Mol Biol Evol 2008, 25:1253-1256.

39. Akaike $\mathrm{H}$ : A new look at the statistical model identification. IEEE. Trans Automat Contr 1974, 19:716-723.

40. Posada D, Buckley TR: Model selection and model averaging in phylogenetics: advantages of Akaike information criterion and Bayesian approach. Syst Biol 2004, 53:793-808.

41. Huelsenbeck JP, Larget B, Miller RE, Ronquist F: Potential applications and pitfalls of Bayesian inference of phylogeny. Syst Biol 2002, 51:673-688.

42. Page RDM: TREEVIEW, An application to display phylogenetic trees on personal computers. CABIOS 1996, 12:357-358.

43. Shang LM, Peng WP, Jin HT, Xu D, Zhong NN, Wang WL, Wu YX, Liu Q: The prevalence of canine Leishmania infantum infection in Sichuan Province, southwestern China detected by real time PCR. Parasit Vectors 2011, 4:173.

44. Welch RJ, Anderson BL, Litwin CM: Rapid Immunochromatographic Strip Test for Detection of Anti-K39 Immunoglobulin G Antibodies for Diagnosis of Visceral Leishmaniasis. Clin Vaccine Immunol 2008, 15:1483-1484.

45. Anders $\mathrm{G}$, Eisenberger $\mathrm{CL}$, Jonas F, Greenblatt $\mathrm{CL}$ : Distinguishing Leishmania tropica and Leishmania major in the Middle East using the polymerase chain reaction with kinetoplast DNA-specific primers. Trans $R$ Soc Trop Med Hyg 2002, 96(Suppl 1):S87-92. 
46. Disch J, Pedras MJ, Orsini M, Pirmez C, de Oliveira MC, Castro M, Rabello A: Leishmania (Viannia) subgenus kDNA amplification for the diagnosis of mucosal leishmaniasis. Diagn Microbiol Infect Dis 2005, 51:185-190.

47. Nasereddin A, Jaffe CL: Rapid diagnosis of Old World Leishmaniasis by high-resolution melting analysis of the 7SL RNA gene. J Clin Microbiol 2010, 48:2240-2242.

48. Francino O, Altet L, Sánchez-Robert E, Rodriguez A, Solano-Gallego L, Alberola J, Ferrer L, Sánchez A, Roura X: Advantages of a real-time PCR assay for diagnosis and monitoring of canine leishmaniosis. Vet Parasitol 2006, 137:214-221.

49. Fraga J, Montalvo AM, De Doncker S, Dujardin JC, Van der Auwera G Phylogeny of Leishmania species based on the heat-shock protein 70 gene. Infect Genet Evol 2010, 10:238-245.

50. Lukeš J, Mauricio IL, Schőnian G, Dujardin J-C, Soteriadou K, Dedet J-P, Kuhls K, Tintaya KWQ, Jirků M, Chocholová E, Haralambous C, Pratlong F, Obonik M, Horák A, Ayala FJ, Miles MA: Evolutionary and geographical history of the Leishmania donovani complex with a revision of current taxonomy. Proc Natl Acad Sci USA 2007, 104:9375-9380.

doi:10.1186/1756-3305-5-75

Cite this article as: Sun et al:: Prevalence of canine leishmaniasis in

Beichuan County, Sichuan, China and phylogenetic evidence for an undescribed Leishmania sp. in China based on 7SL RNA. Parasites \& Vectors 2012 5:75

\section{Submit your next manuscript to BioMed Central and take full advantage of:}

- Convenient online submission

- Thorough peer review

- No space constraints or color figure charges

- Immediate publication on acceptance

- Inclusion in PubMed, CAS, Scopus and Google Scholar

- Research which is freely available for redistribution 